() LANGUAGE CHANGES

\title{
Reasons for Endangerment of Manchu and Hezhe Languages
}

\author{
Zhao Aping * $\quad$ Zhang Yingying **
}

\begin{abstract}
In the Tungus-Manchu group, the endangerment of Manchu and Hezhe languages has been confirmed in the linguistic circles in China. Today, only aged people in some Manchu and Hezhe villages of Heilongjiang Province speak these two languages. This paper explores and analyzes the reasons for the endangerment of Manchu and Hezhe languages and provides evidence of the general rules of language endangerment. The research shows that social, psychological and linguistic factors work together to endanger the two languages. Their switch and variation modes have jointly endangered themselves, and the gradual and sudden changes in their linguistic systems have played a joint force. This paper is significant as a reference for further research into universal rules for the endangered languages.
\end{abstract}

Key words: the Manchu language, the Hezhe language, language endangerment, reasons

\section{Introduction}

A language is the most important communication tool for mankind. Its application acts as one of the prerequisites to build up the society, and its evolution is linked closely to the social progress. Ye Feisheng \& Xu Tongqiang (1997:175) also mentioned that the social progress is the foundation and motivation of development of a language. Disintegration, unification and contact of societies accordingly result in the disintegration, unification and contact of languages.

The Manchu and Hezhe languages have been affected, assimilated and replaced when in contact with the Chinese language and other interrelated languages. With changes of social and even ecological environment, the Manchu and Hezhe people have turned to use Chinese, and then their ancestral languages degenerate in communication functions and fall

\footnotetext{
${ }^{*}$ Zhao Aping: Manchu Language and Culture Research Center, Heilongjiang University, Harbin, 150080, China. E-mail: zhaoaping19@126.com.

${ }^{* *}$ Zhang Yingying: School of Foreign Languages, Nanjing Audit Institute, Nanjing, 210029, China. E-mail: Catherine_zyy@hotmail.com.
} 


\section{Reasons for Endangerment of Manchu and Hezhe Languages}

into danger. According to the latest researches on the Manchu language, today no more than 100 persons speak it, and most of them are the aged people who live in Sanjiazi Village in Fuyu County, Xiamachang and Dawujia Manchu villages in Heihe. According to a research in 2001, 4.20\% of contemporary Hezhe people can speak Hezhe language in Heilongjiang Province, while this percentage fell to $3.54 \%$ nationwide (Hezhe population amounted to only 4060 throughout China in 2000). In the 1980s, the usage of Hezhe language has been narrowed down to special occasions and individual families. In the early 21 st century, people who speak the Hezhe language are seen as talents, because only few Hezhe people can use their language. It can be seen that in China the Hezhe language has become endangered, as well as the Manchu language.

This paper explores, analyzes and compares the reasons for the endangerment of Manchu and Hezhe languages and may provide evidence of the general rules of language endangerment. The reasons of evolution of a language can be analyzed from factual (physics), cultural, psychological and linguistic aspects (Ma Qinghua, 2006: 3-13, 43-52). This guides us to study and compare reasons for the endangerment of the Manchu and Hezhe languages. In this paper, we conclude the reasons come from social aspects like reality and culture, psychological aspects, and the inner reasons of the two languages. The inter-effects of these reasons have resulted in degenerated communication function and endangered them.

\section{Social reasons}

As a communication tool, a language's existence and evolution is always guaranteed by its users' (that is to say, its language community) usage and preservation. Contacting with another language community, the scale of the original users may decrease. Once a language community is subject to such changes, its communication role is bound to diminish. The Manchu and Hezhe languages are endangered by a decreasing number of their ancestral language users and an increasing number of those turning to use Chinese.

Our researches and statistics show as following: firstly, as to the percentage of Manchu and Hezhe people who do not speak Manchu \& Hezhe languages, more than $80 \%$ of them have turned to use Chinese $-99.99 \%$ for Manchus and $85.22 \%$ for Hezhes ${ }^{\circledR}$. In addition,

\footnotetext{
(1) Another research on the usage of the Hezhe language carried out between 2001 and 2002 in four villages (Jiejinkou, Bacha, Sipai and Aoqi), two cities (City of Jiamusi and Tongjiang), a town (Raohe) and a county (Fuyuan), shows $94.26 \%$ of the Hezhe population have turned to use the Chinese language. (Wu Baozhu 2003)
} 
this percentage tends upwards; secondly, as to the age range of the two ancestral languages users, only the middle-aged and aged can understand them - they merely remember hundreds to thousands of words, some phrases, and several sentence patterns to record parts of ballad literature. Furthermore, their younger generations have lost this ability; thirdly, Manchus and Hezhes only have listening ability in their own language, while they are very poor in speaking. Because less and less Manchus and Hezhes use their ancestral languages, opportunities for using their ancestral languages have been reduced, and the communication functions of the two languages have degenerated. This is the phenomenon that is endangering the Manchu and Hezhe languages, and also the main reason why these two languages are endangered (Zhao Aping \& He Xuejuan, 2007a). So why are there fewer Manchu and Hezhe language users and why do they use Chinese? The following social reasons can provide an explanation.

\subsection{Inter-racial neighborhood \& population ratio between racial groups}

Two-way migration has brought about inter-racial neighborhoods, which weaken the social institution which protects its ethnic language. In such a context, in order to communicate between ethnic groups, a tool for communication should be changed, unless there is to be no communication between tribes. Within an inter-racial neighborhood, population ratio between ethnic groups determines which ethnic language is to surpass the other. When the population of an ethnic group holds no predominance in the neighborhood, its language community is subordinate to that of a larger population group, and its ethnic language to that of the larger group.

From the late 16th to the early 17th century, the Manchu Minority merged with the Jurchen people as its main body and became the ruling class in the Qing dynasty. On one hand, the Manchus began immigration into the Han community, after Qing troops marched into Central China in 1644. A large quantity of Manchus, who had isolated themselves in the three Northeast provinces (Heilongjiang, Jilin, and Liaoning) trickled into the inland and were scattered over the whole country. Living with Hans, Manchus became mixed and mingled with them. Communication between two peoples thus broadened. With a smaller population, the Manchus were encircled by a larger population of Hans, which undoubtedly determined the Manchu language's conversion to Chinese. On the other hand, the Hans' emigration to the Manchus' compact community during the early period of the Qing dynasty, was caused by the vast land in Northeastern China wasted after Qing troops' exodus. To restore agricultural production as early as possible and to sustain the Manchus staying there, the Qing government began to mobilize vagabonds to cultivate wastelands. 


\section{Reasons for Endangerment of Manchu and Hezhe Languages}

In the year of 1928, the Republic of China government promulgated "Trial Regulations for Cultivating Wastelands Bordering Heilongjiang Province", which led the unprecedented immigration boom into Heilongjiang Province. From 1927 to 1929, 1.12 million immigrants reached the location. As a result, the Manchus staying there melted. The two-way migration on large scale between the Manchu Minority and other ethnic groups (primarily Han) greatly changed the linguistic and social environments of Manchus, bringing Chinese language and its culture. The blending of the Manchu language and Chinese was inevitable. For a certain period, Manchus were bilingual - using the Manchu language as well as Chinese; gradually they switched to Chinese only. In late Qing dynasty, the majority of Manchus had given up their ancestral language, leaving only a handful of Manchus in some parts of Heilongjiang Province.

The village Sanjiazi in Fuyu County of Heilongjiang Province is the best place which preserves the Manchu language. Due to its remote location and poor transportation, where a dirt road was not built until the 1950s, there were relatively fewer immigrants. This as a matter of fact offers natural barriers for the ancestral language in the village. The village was built in the reign of Emperor Kangxi and settled by 3 families - families of JI, MENG and TAO (another saying JI, MENG and FU), who originally serviced in navy battalion stationed in Qiqihar. Later, Manchu people with family names of GUAN, WU, FU, ZHAO, BAI etc. moved there. At the very beginning, as soldiers in 8 Banners commanded by General Sabusu in Heilongjiang Province, these villagers and their descendants could all speak the Manchu language very well (Zhao Jinchun,1999). After 1980s, more and more immigrants speaking Chinese came and they changed the original linguistic environment in the village. In 1961, Manchus amounted to $84.7 \%$ of the whole population there, while in 1986 it decreased to about 50\%. This kind of interracial neighborhood spoiled the usage environment of the Manchu language and speeded up the use of Chinese. In July 2002, the authors researched the situation of the Manchu language in Sanjiazi. They found that Manchus and Hans are the majority peoples in the village, and there are one hundred and eighty-six Manchus who know about their ancestral language or can use it. The number of these people is only $42 \%$ of the Manchu population (442 people) and $18 \%$ of the whole village (1034 people) (Zhao Aping, Guo Mengxiu \& Tang Ge, 2002). (Now the number of people using Manchu language in Sanjiazi has be reduced to less than a hundred).

Likewise, Hezhes' emigration and non-Hezhes' immigration also affect the usage of the Hezhe language. Similar to the Manchu Minority, the Hezhe Minority has been long encircled by Hans and then mingled with them. Hezhe ancestors inhabited and multiplied 
in the 3 Rivers Basin (Heilong River, Songhua River \& Wusuli River) since ancient times. In the Qing dynasty, Hezhes primarily lived in compact communities, which helped to maintain their language. As to their emigration, during Japan's invasion, Hezhes were forced to move. Though migrating in ethnic groups, the population of Hezhes decreased sharply due to poor conditions in the new areas and natural disasters. Migration disintegrated the Hezhes and then they had to mix with other ethnic groups. After 1949, Hezhes still mainly inhabited Heilongjiang Province. In 2000, the 5th national census figured there are 3,910 Hezhes in Heilongiang Province, which is $84.27 \%$ of the total Hezhe population. After "Trial Regulations of Cultivating Wastelands Bordering Heilongjiang Province" in 1928, 462,000 immigrants settled in lower Songhua River, Wusuli River Basin and Heilongjiang Basin. Later a large number of non-Hezhes moved into the Hezhes' living area, gradually narrowing the usage scope of the Hezhe language. After 1949, though Hezhes still stayed in small compact communities, non-Hezhes increased in percentage year by year. Gradually Hezhes mingled with other ethnic groups. For example, in 1958, Hezhes amounted to $33.67 \%$ of the whole population in villages Jiejinkou, $75.42 \%$ in Bacha and $74.81 \%$ in Sipai. At that moment, Hezhes was still bilingual. "Combined Brief History of Hezhe Minority" (1959) states that "living together with Hans, Hezhes, old or young, man or woman, have already mastered Chinese and can use it to communicate freely. Younger Hezhes are taught to use it since they are little. Schools offer courses in it, and students learn it with no difficulty". However the research papers from 1982 and 1983 show that "living with Hans, Hezhes already use Chinese to communicate orally and on paper. They seldom use their ancestral language except on specific occasions. Generally speaking, today those over 55 years old can still use their ancestral language; those between 40 and 55 can understand it or can merely speak some simple phrases; and those under 30 know little of it or even ignore it completely". (An Jun, 1986) A 2001 survey showed only $3.54 \%$ of Hezhes still mastered their ancestral language. In 2003, in Village Jiejinkou, the Hezhe population had been reduced to $28.75 \%$ of the total and $36.36 \%$ in Sipai (He Xuejuan, 2007).

Nationwide, the Manchu population lists second among all the minorities (just after the Zhuang Minority). Compared to the Hezhe population, the Manchu Minority counts as big; while compared to the dominant Han in China, it deserves its name - a minority. According to the 4th census of Chinese Mainland in 1990, the Manchu population amounted to 9,846,800, the Hezhe Minority 4,200, and Hans 1,133,682,500. In 2000, the 5th census of Chinese Mainland found 10,682,200 Manchus, 4,640 Hezhes and, 1,159,400,000 Hans. 


\section{Reasons for Endangerment of Manchu and Hezhe Languages}

\subsection{Inter-racial marriages}

Inter-racial marriages promote the merging of ethnic groups, which speeds up the endangerment of a language. After Qing troops entered China, the Manchu Minority admitted a large number of non-Manchus via inter-racial marriages. During his 5th year of reign, Qing Emperor Shunzhi (1648) told the Ministry of Rites: "Recently, we are the world,...Years hence, Manchus and Hans, of high ranks or humble positions, who would like to marry, be allowed" ("Memoir of Qing Emperors"). Furthermore, Manchus admitted large groups of Hans by various ethnic fusions. Many families changed their ethnic make-ups due to inter-racial marriages. This kind of fusion between ethnic groups speeded up Manchus in speaking Chinese.

Similarly, inter-racial marriages had been common in the Hezhe Minority. Before the Qing Dynasty, Tungusic Minorities,Mongolians, Hans, etc. inhabited the regions where the Hezhes settled. Inter-racial marriages between tribes and ethnic groups had become common, for which we found no supporting data though. Ling Chunsheng (1934) mentioned inter-racial marriages. Gathering the physical type of 52 people in the vicinity of Fukejin, LING found the majority were of mixed origin, and that there the Hezhe language had created technical names for the first, second, third and fourth generation of people of mixed origin. Obviously, inter-racial marriages had not been temporary or by accident. Yang Jinchu (1993) investigated the marriage status in three villages (Jiejinkou, Bachu \& Sipai) where Hezhes clustered. He found that inter-racial marriages between fishermen amounted to $81.36 \%$ on average, and those between government staff members $71.92 \%$. As time went by, inter-racial marriages in the Hezhe Minority tended to expand. From 2003 to 2004, we researched the marriage status in the Hezhe compact villages called Jiejinkou, Bacha, Sipai, Aoqi and Zhuaji. There, besides Hans, inter-marriages had become common between Hezhes, Manchus, Mogolians, Koreans, Huis as well as Tujias. They had all turned to use Chinese. ${ }^{(1)}$ As an ethnic language, whether used in families underlies its survival and development. A linguist of the Soviet Union stated that "putting an end to its usage in families, a language tends to die. If children are not taught their mother tongue and do not learn to use it in families, a language is certain to die." (He Junfang, 2002) It has proved that inter-racial marriages have strengthened the Chinese language's influences on the Hezhe language, since Chinese has been adopted as a common language to communicate between ethnic groups.

\footnotetext{
(1) In bordering areas where ethnic groups mingle, Manchus, Hans and Koreans all communicate in public in Chinese (Zhao Jie,2000).
} 


\subsection{Comparison of strengths and weaknesses between cultures}

Cultural strain (Ma Qinghua, 2006:9) contributes an important force to promote a language's conversion, its being deserted and its endangerment. Evolving from several thousand years of civilization, the Han culture develops profoundly. During the Qing dynasty, though Manchus ruled the Hezhes and Hans, the Han culture still held advantages over the Manchu and Hezhe cultures. Such a cultural strain finally forced the Manchu and Hezhe languages to succumb to Chinese. This indicates that the comparative strengths and weaknesses between cultures affects a language's conversion, which sometimes overwhelms the effects of political strengths. A stronger cultural community has greater expressive power, while a weaker one lacks expressions for a variety of concepts. Only rapid innovations and developments can sustain a language's expressive demand, which requires great social cost and does no good to the smooth interactions with stronger cultural communities.

When Manchus established the Qing dynasty in Northeastern China, the Manchu culture held majority and dominance. As a ruling class, they demanded non-Manchus in their governance to master the Manchu language, the national language at that time. Hans migrated there by force, and officers as well as Chinese soldiers captured had gradually been Mechuized. (Wang Zhonghan, 1988) Then Manchus began to rule the whole of China. Confronted with the Hans' powerful culture, the Manchu culture was overshadowed. At the beginning of the Qing dynasty, its language and culture were privileged, since its oral form and written form were used nationwide as the "National Language" and "Qing-style writing". Under the powerful strain of the Han culture, since the reign of Qing Emperor Qinglong, the Manchu language had to decline, which drew great attention of the ruler. To sustain its position as the national language, the Qing government adopted a series of measures, namely, to fight off loanwords from Chinese (mainly 3 methods were adopted: to replace them with new words; to reform them in Manchu style; to produce new words to distinguish the ambiguity of the borrowed ones) (Ji Yonghai,2006). Unfortunately, it was in vain and before long Manchus began to use the Manchu language and Chinese bilingually, and finally they turned to use Chinese monolingually.

Under the ruling of the Manchus, Hezhes had long been regarded as part of the big family. Before Qing troops entered Central China, aborigines of the Hezhe accepted the reorganization from Manchus; most of the Hezhe aborigines left Wusuli River and Heilongjiang Basin, where they had multiplied since ancient times. Due to migration, they became the earliest group who lost their ancestral language. The Qing government 
established political offices in the regions where Hezhes lived and assigned chieftains of Hezhe tribes to take important positions. The new life style of these Hezhe officers who had left their ancestral river basins was very different from their fishing and hunting style. Years later, their daily habits and customs changed greatly and a lot of them applied to be a member of the Manchus. They turned into a crowd who lived not far from their homeland but not speaking their ancestral language. With Manchus' moving into China's mainland, the stronger cultures changed. Like the Manchus, Hezhes gradually turned to use the Chinese language.

\subsection{Frequent interactions brought by social prosperity}

Since 1980s, isolated Manchu villages - such as Sanjiazi - have increased their income and improved their living standards (Jiang Chenghou, 1990 \& Ji Yongchang, 1999), which greatly opened the villagers' horizons. They began to learn about the Chinese culture and the wonderful world outside, which involved them into the more opening-up and prosperous social system. Convenient transportation and advanced communication networks further offered them opportunities to contact the outside. All these reformative activities inevitably engaged people with communities speaking Chinese, so they had to use Chinese, which lessened the opportunities for them to use the Manchu language. Rapidly the communication function of the Manchu language deteriorated. In the year of 1997, in the Village Sanjiazi, its usage was extremely restricted and it had become endangered there. With social economical growth, the village will progress and become much more innovative, rather than retreat to the ancestral state - isolated and backward. As a result, the environment for the Manchu language cannot be restored and it is bound to become extinct, the same as the Hezhe language experience.

\subsection{Lexical shift caused by economic restructuring \& civilization developing}

Economic restructuring deprives a great number of ethnic language words of their vitality; meanwhile it rapidly brings many new words. The ethnic language can not produce large quantities of words at once, and then it has to borrow existing words and expressions from other ethnic groups with a stronger culture. The Manchu language originated in a time of the fishing-and-hunting economy.There are extremely abundant animal-related words. Take "deer" as an example. The Manchu language has more than 31 generic names for it. Besides the general name, the language has specific words to refer to deer differing in size, kind, age, color and usage, such as suwa buhu (spotted deer), iren (horned deer), fiyaju (baby deer), urgesen (yearling deer), solonggo (two-year-old deer), lorbodo (three-year-old deer). 
Referring to dogs, it has taiha (dogs having long hair on tail and ears), yolo (dogs having thick and long hair on body and tail, big ears and droop lip), peseri (baby crossbred from yolo with another kind of dog), durbe (dogs having two small patches of white or yellow hair on the eyebrow), kuri (dogs having the same flecks like panther), palta (dogs only with a few flecks on the bridge of nose), cakv (dogs with a neck all white), kalja (dogs having white hair backward along the forehead), etc.

Similarly, there are 11 generic names for boars, nearly 50 for hawks and eagles, and more than 70 for freshwater fish. (Notes on Qing Writing, 1957; Zhao Aping, 2006) With Manchus' migrating into the province of Liaoning, their economy evolved to an agricultural stage, and then they replaced the original fishing-and-hunting economy with the farming one. The words and expressions originally suitable for the fishing-and-hunting economy gradually died after their entrance into Central China. Investigations on current Manchu language in Village Sanjiazi show no one there can speak or remember the above-mentioned words featuring the fishing-and-hunting economy (Zhao Aping, 2000-2006). On the other hand, great advances in modern civilization promote the Manchu language to loan words from Chinese on a large scale (see below).

The Hezhe language also experiences rapid changes of economic patterns. Ancient Hezhes lived on fishing or hunting, and later they mainly earned their living by fishing. With changes of ecological environment and the opening-up policy since the last century, the Hezhes adopted a new economic pattern characterized by fishing-economy in primary, self-sufficient foodstuff and diversification. The percentage of natural fishery decreased year by year while the number of population involved in the branches of intellectual production as well as tertiary industry increased. Terms in Chinese related to crop plantation, raising livestock and service industry kept entering into the Hezhe language. Original words in the Hezhe language related to the traditional fishing industry have found new expressions in Chinese, e.g. the tools used in the fishing industry (such as new net utensils and boat models), the transaction of products (like jargons used in dealings), daily utensils of fishermen (such as dieting, living and the like). Meanwhile, due to the declining fishing industry, many fixed expressions were lost in the Hezhe language. During the evolution, newly-born terms were all expressed in Chinese. The Hezhe language was greatly struck and reduced in its communicative function.

\subsection{Impacts of language used in media and teaching}

Due to the social circumstances mentioned above, the national psychological reasons (see below), and lack of words or functions of their ancestral languages, Manchus and 


\section{Reasons for Endangerment of Manchu and Hezhe Languages}

Hezhes all use Chinese in media and teaching. This tremendously endangered the two languages. Take Village Sanjiazi as an example, which is one of the Manchu compact communities surrounded by the Chinese language and its culture. There only a few people can use the Manchu language within families. However, they cannot pass it on, for they do not know its written characters. Documents, articles, daily radios, newspapers, TV programs, and the like all are in Chinese. At school, students are mainly taught the Chinese language and its culture. Adolescents totally lose the opportunity to learn their ancestral language in formal education. Undoubtedly the Manchu language was greatly striken. Historically, the Chinese language exerted effects on it via education, which could be traced back to the Qing dynasty when basically the selection-through-imperial-examination system was adopted. With the spreading of this system, more and more Manchus took pride in memorizing "The Four Books" (The Great Learning, The Doctrine of the Mean, The Confucian Analects, and The Works of Mencius), "The Five Classics" (The Book of Songs, The Book of History, The Book of Changes, The Book of Rites, and The Spring and Autumn Annals), and in writing out perfect Bagu essays (rigid in style). Quite a few Manchu intellectuals succeded to become officers through the imperial examination, although they were privileged to be officers without taking it. This as a matter of fact promoted the Chinese language and its culture (Zhang, 2008).

The Hezhe language had never been written. The current language came from those of the ruling class - the Chinese characters. Chinese is used in social documents and literature, and in all education. The Hezhe language lost its usage in politics, culture and education. Hezhes no longer use their ancestral language widely. Only a few Hezhes can use it.

\section{National psychological reasons}

Analyzed from subjective aspects, the idea of opening-up results in a language's conversion, abandonement and endangerment. Manchus' spirits favor progress, diligence and opening-up. They would like to take in excellent cultures from the outside, and they especially appreciate the long and profound Chinese culture. Meanwhile, as a rising minority group which became the ruling class in a feudal dynasty, the Manchus needed to learn and master the advanced Chinese language and its culture as soon as possible. From Chinese characters to its customs, Manchus imitated all without exception, like politics, economy, culture, customs, family names, costumes, dieting, etc. The inter-mix between Manchus and Hans lies not only in the language,. With the progress of modern economy and culture, the middle-aged Manchus change their values toward their ethnic language. 
Unlike their parent generation, they no longer maintain it; instead, they gradually decline it and even give it up to accept Chinese. Manchu teenagers have basically abandoned their ethnic language. The inferior position of Manchus' ethnic language among its people could be indicated from the way they call their language. The Chinese sentence pattern takes the sequence of SVO structure, while the Manchu language takes the SOV. Manchus in the Village Sanjiazi call their ancestral language Foreign Language (Chao Ke \& Zhao Aping,2002), rather than thinking of Chinese as the foreign one. Language users decrease their sense of identity with their ancestral language, which subjectively deteriorates a language and endangers it.

Seen from the imminent endangered process of the Hezhe language, Hezhes may not have been forced to give up their ethnic language. Weak national consciousness and indifferent concepts of the ethnic language led Hezhues to change their language.

\section{Inner reasons in languages}

Being a communication tool, a language is likely to evolve with social development. "With social progress, new substances and concepts mushroom. People tend to think in a way more and more complex and detailed. All these require higher form of communication, and promote a language to expand its lexicon and to improve its grammar." (Ye Feisheng \& Xu Tongqiang, 1997:174) Having reduced its communication function, the fixed features of an ethnic language are bound to deteriorate.

Communicable changes in both Manchu and Hezhe languages originated in loan words. "Non-systematic Characters in Jurchen Tribes" in Translations to Tribal Languages compiled in $14^{\text {th }}$ century show that loan words from Chinese had amounted to about $10 \%$ in the Manchu language (Zhao Jie,1988). Till the late 19th century, it is estimated that the number of loan words had amounted to about $1 / 3$ of the total Manchu language, which exceeded those from Mongolian, Tibetan, Sanskrit and the like (G.P. Moellendorff,1892:3). Until the late 20th century, the modern Manchu language had borrowed almost 50\% from Chinese (Zhao Jie, 1988). In the Village Sanjiazi, large quantities of such loan words increasingly entered the Manchu language, which marked its fixed features' deterioration. This could be seen through the language's whole evolution. Nowadays as the only surviving Manchu dialect, the language in the Village Sanjiazi received no strong support for usage in larger areas or a wide scope, which means it was able to produce very few new words. When there were difficulties in expressing oneself, words were loaned from Chinese, which occurred in the late 60 s and aggravated since the late 80 s. "In the Manchu 


\section{Reasons for Endangerment of Manchu and Hezhe Languages}

language, a great number of fixed expressions disappeared and a large number of loan words entered from Chinese." (Ji Yonghai \& Bai Liyuan, 1990:227) In Village Sanjiazi, the Manchu language lexicon is dominated by Chinese words. The production of new words with Manchu phonemes is limited to trivial and individual cases (EN Hebatu,1995:21).

In Village Sanjiazi, the morphology of the Manchu language is greatly struck by large quantities of loan words from Chinese and by the deterioration of fixed features in its lexical system. The original agglutinative language loses its affixes, and the ones remainining are restricted in number, but they express multi-concepts. It is frequently seen that the same affix expresses different grammatical meanings. (Zhao Aping \& Chao Ke, 2001) In addition, a large number of loan words from Chinese helps to simplify the multi-syllabic words in the Manchu language. This further promotes the phonemic complexity and free stress, which in turn motivates the disintegration of vowels and rhymes. Finally the phonology in the Manchu language disintegrates and intermixes. (Zhao Jie, 1992) All these chain effects speed up to endanger the Manchu language.

Having declined in communicative ability, the lexical and structural system in the Hezhe language greatly changes, which can be seen in the lexicon, grammar and pronunciation. Its fixed expressions have had no additions for quite a long time, and thus maintaining them becomes rather difficult. On the other hand, it finds additional loan words year by year, which situation becomes more and more distinctive. With its fixed resources and patterns, there is no chance to produce new words in the Hezhe language (Jiang Hongbo, 1990). As agglutinative as the Manchu language, the Hezhe language features rather complex morphological changes, such as cases and number for nouns, tense, voices and moods for verbs. However, its structure changes greatly as it is endangered under the impacts of foreign languages. A decreasing number of fixed expressions results in its morphological changes: the dropping of number, case and possession for nouns and adjectives, irregular inflection for verbs, and many adverbs, postpositions and conjunctions have been replaced by their counterparts in Chinese (Zhao Aping \& He Xuejuan,2007b). The deserted lexical and morphological categories have been replaced with their Chinese counterparts, which greatly changes the phonetic system of the Hezhe language. Its vowels and rhymes disintegrate, its stresses become unstable, and compound vowels and consonants abound. Such variations in lexicon and morphology, and lasting effects of Chinese, contribute to its syntactic changes. Critical loss of the fixed constitutes or features in its pronunciation, lexicon, syntax and the like, paralyzes its whole system, which finally deprives its usage and endangers it (He Xuejuan, 2000-2005). 
Both the Manchu and Hezhe languages produce new words by borrowing as their principal source. The fixed expressions in these two languages have been dropped and many of them have been replaced with foreign ones. Obviously, this borrowing does not mean supplementing to their insufficient expressions, but converging the two languages to the transference ones. Language fusion requires this, and as a result the two languages reduce their ability to regenerate expressions, which brings about chain effects in the morphology, syntax and pronunciation. Such a borrowing model in endangered languages differs in essence from the one in non-endangered languages. As is known to all, in the latter supplements of new words are added to the insufficient expressions in the original language.

The cases of the Manchu and Hezhe languages indicate that a language's transference which results in its endangerment finds root in a large number of borrowed or transferred words. This is in accordance with the basic principle of the "Lexical Diffusion" theory put forward by W. S-Y. Wang (1969). He held that communicable changes of a language system originate from the lexical changes. During its evolution, fixed expressions of a language gradually retreat and then foreign elements fill in.

\section{Conclusion}

As analyzed from above, the endangerment of the Manchu and Hezhe languages finds similar reasons, coming from society, psychology, inner reasons and the like. As a communicative tool, a language always requires its users' usage and maintenance (a language community) to sustain and to improve. Once its user community changes in population relative to that of other language groups in contact, the interactive function of the weaker language tends to decline. In reality, fewer users are the result of a smaller population base, interracial neighborhood, inter-racial marriage, cultural strain, frequent interaction brought by prosperous economy, culture, etc. Besides, use of foreign languages in media and education speeds up the decline of an ancestral language when competing. Finally, this accelerates the endangerment of the ancestral language. In addition, the opening-up national psychology as well as liberal attitudes toward other languages constitute subjective reasons for a language's trade-off and its transference. All the above mentioned reasons are non-linguistic contributors to an endangered language. Seen from the inside of a language, a larger number of borrowed or transferred words foreshadows a language's transference and even its endangerment. This triggers chain effects in morphology, syntax and pronunciation of a language. Observed from the outside, 


\section{Reasons for Endangerment of Manchu and Hezhe Languages}

Manchu-Chinese transference originated from monolingual usage of the Manchu language, later developed to bilingual usage of the Manchu and Chinese, and finally turned to monolingual usage of Chinese. However, when the fixed expressions of the ancestral language gradually are reduced and foreign elements filled in. Seen from the inside again, this track seemingly began with the Manchu language, later evolved to the Manchu language with Chinese style, then the Chinese language with Manchu style (Zhao Jie, 2001: 52-76), and last transferred to Chinese. To put this in detail, on the first stage of transference, the Manchu language was used monolingually; then the Manchu language and Chinese were used bilingually, when the Manchu language to some extent represented some Chinese characteristics; last Chinese was used monolingually, when initially it showed some properties of the Manchu language. In conclusion, Manchu-Chinese transference in reality finds joint contributors - the system shift model (the first track) and the system evolution model (the second track), that is to say, the joint efforts of sudden and gradual changes in a language system. This paper is a worthy reference to further explore and understand the universal rules in the reasons for the endangerment of languages.

\section{References}

An Jun. 1986. Brief Notes of Hezhe Language. [M] Beijing: Ethnic Publishing House.

Chao Ke \& Zhao Aping. 2002. Researches \& Studies on Endangered Ethnic Languages in China-Research Report on Current Manchu Language. [J] Manchu Studies. No. 2.

He Junfang. 2002. Analysis on Social \& Cultural Contributors to Loss of Hezhe Language. [J] Journal of Minzu University of China. No. 2.

He Xuejuan. 2002-2005. Research Data on Usage of Hezhe Language in Cites of Jiamusi \& Shuangyashan by Hezhe People. [R]

He Xuejuan. 2007. Current Hezhe Population \& its Development. [J] Journal of Dalian Nationalities Institute. No. 2.

Investigation Team on Society \& History of Ethnic Minorities in Heilongjiang Province, Ed. 1959. Combined Brief History of Hezhe Minority. [Z]

Ji Yongchang. 1999. 50-Year-History of Fuyu County. [Z] Harbin: Heilongjiang Press and Publication Administration.

Ji Yonghai. 2006. On loan Words in Manchu Language from Chinese. [J] Manchu Studies. No. 1.

Ji Yonghai \& Bai Liyuan. 1990. On Relationship between Manchu language and Chinese in Village Sanjiazi. [A] Dept. In Three of Literature in Ethnic Minorities \& Ethnic Languages Research Center of China Central University for Nationality (ed.): Studies on Relationship between Ethnic Languages and Chinese. [C] Journal of China Central University for Nationality.(sup.)

Jiang Chenghou \& Ji Yongchang. 1990. Brief of Fuyu County. [Z] Beijing: Chinese Communist Party History Publishing House.

Jiang Hongbo. 1990. Studies on Current Hezhe Language \& its Development. [J] Manchu Studies. No. 2.

Ling Chunsheng. 1934. Hezhe Minority in Lower Songhua River. [M] Nanjing: Independent Periodical (A) of Division of History and Language in National Research Institute.

Ma Qinghua. 2006. Multidimensional Research on Semantics. [M] Beijing: Language and Culture Press.

Memoir of Qing Emperors. 1985. [Z] Beijing: Zhonghua Book Company.

Moellendorff, P.G. 1892. A Manchu Grammar. [M] Shanghai: American Presbyterian Mission Press. 


\section{Zhao Aping Zhang Yingying}

Notes on Qing Writing. 1957. [M] Reign of Emperor Qianlong. Publishing House of Minorities. copy. Wang, W.S-Y. 1969. Competing Changes as a Cause of Residue. [J] Language.Vol. 45.

Wang Zhonghan. 1988. Compiled Studies on History of Manchu Minority. [C] Beijing: Publishing House of China Social Sciences.

Wu Baozhu. 2003. Research \& Analysis on Current Hezhe Language. [J] Manchu Studies. No. 2.

Yang Jinchu. 1993. Current Social, Economic \& Cultural Development in Fishery Hezhe Villages and Outlooks: Research Report on Hezhe Minority in Hezhe Villages Jiejinkou, Bacha \& Sipai. [J] Heilongjiang Nationality Series. No. 3.

Ye Feisheng \& Xu Tongqiang. 1997. Outline of Linguistics. [M] Beijing: Peking University Press.

Zhao Aping. 2000-2006. Research Data on Current Usage of Manchu Language in Village Sanjiazi of Damanke Town, Fuyu County, Heilongjiang Province. [R]

Zhao Aping, Guo Mengxiu \& Tang ge. 2002. Urgent Research on Manchu-Tungusic Language \& CultureResearch Report on Manchu Language and its Culture in Village Sanjiazi of Fuyu County. [J] Manchu Studies. No. 2.

Zhao Aping. 2006. Manchu Language, its History \& Culture. [M] Beijing: Ethnic Publishing House.

Zhao Aping \& Chao Ke. 2001. Research on Current Manchu Language in Heilongjiang Province. [M] Harbin: Publishing House of Heilongjiang Education.

Zhao Aping \& He Xuejuan. 2007a. Comparison \& Analysis on Reasons for Endangerment of Manchu and Hezhe Languages. [J] Manchu Studies. No. 1.

Zhao Aping \& He Xuejuan. 2007b. Analysis on Cases \& Tenses of Endangered Manchu and Hezhe Languages. [J] Manchu Studies. No. 2.

Zhao Jie. 1988. On Development of Loan Words in Manchu Language from Chinese. [J] Linguistic Researches (Yuwen Yanjiu). No. 3.

Zhao Jie. 1992. Penetration of Chinese Language \& Chain Effects in Phonology in Manchu Language. [J] Linguistic Researches (Yuwen Yanjiu). No. 4.

Zhao Jie. 2000. Collection of Manchu Language in Bordering Areas. [J] Minority Languages of China. No. 3.

Zhao Jie. 2001. Chinese Linguistics. [M] Zhaohua Press.

Zhao Jinchun. 1999. Brief History of Village Sanjiazi. [J] Cultural \& Historical Data of Fuyu County. No. 7. 